Marquette University

e-Publications@Marquette

School of Dentistry Faculty Research and

Publications

Dentistry, School of

$2-1-2018$

\title{
Outreach: Change the World, Change Yourself
}

Geoffrey A. Thompson

Marquette University, geoffrey.thompson@marquette.edu

Edward J. Plekavich

Izchak Barzilay

University of Toronto

Accepted version. The Journal of Prosthetic Dentistry, Vol. 119, No. 2 (February 2018): 197-199. DOI. (C) 2018 Elsevier B.V. Used with permission. 
Marquette University

\section{e-Publications@Marquette}

\section{Dentistry Faculty Research and Publications/School of Dentistry}

This paper is NOT THE PUBLISHED VERSION; but the author's final, peer-reviewed manuscript. The published version may be accessed by following the link in the citation below.

The Journal of Prosthetic Dentistry, Vol. 119, No. 2 (February, 2018): 197-199. DOI. This article is (C) Elsevier and permission has been granted for this version to appear in e-Publications@Marquette. Elsevier does not grant permission for this article to be further copied/distributed or hosted elsewhere without the express permission from Elsevier.

\section{Outreach: Change the World, Change Yourself}

Geoffrey A. Thompson

School of Dentistry, Marquette University, Milwaukee, WI

Edward J. Plekavich

Private Practice, Sterling, VA

Izchak Barzilay

Department of Dentistry, University of Toronto, Toronto, ON, Canada

Division of Prosthodontics, Mt. Sinai Hospital, Toronto, ON, Canada

Division of Prosthodontics of the Eastman, Department of Dentistry, University of Rochester, Rochester, NY

The Academy of Prosthodontics is the oldest specialty organization dedicated to prosthodontics. The organization had its origins in the study of complete removable dental prostheses and can count among its early members Drs Milus M. House, C. J. Stansbery, Victor H. Sears, F. M. Hight, Carl O. Boucher, Muller V. DeVan, and many other important prosthodontists of the 20th century. The organization has evolved significantly during its 100 years of existence. Today, the membership includes fellows from around the globe and the Academy's scientific interests reflect the scope of treatment provided by contemporary prosthodontists. 
The Academy's emblem depicts an open book with these four words: Study, Investigate, Promote, and Disseminate. With these charges, the Academy can count among its achievements co-founding the Journal of Prosthetic Dentistry, establishing the American Board of Prosthodontics, and creating "The Glossary of Prosthodontic Terms." An often-overlooked achievement is the creation of a foundation to support education and research. With its beginnings in 1960, it surely must have been one of the first foundations in organized dentistry. In 1991 the foundation included outreach projects among its supported endeavors.

The introduction of fluoride into drinking water and the advent of toothpaste commercials and smiling television personalities led to a dramatic decrease in the number of edentulous people in the United States. At the same time, dental schools were reducing the curriculum devoted to complete denture treatment. Academy members became increasingly concerned that some segments of the population did not have access to quality care. The training and experience of academy members made them well suited for addressing that problem. Thus, they formed the Outreach Committee to provide care for those in need.

Since 1993, the Outreach Program has provided, free of charge, almost 2000 dentures to 1000 patients who otherwise could not afford or did not have access to care. The groups have also provided implants and many relines, repairs, and removable partial dentures. Funding for this work comes from the Academy of Prosthodontics Foundation, generous corporate donations, and members and friends of the academy. However, the restorations are fabricated by outreach teams. Over the years, more than 150 academy members and friends of the academy have contributed their time to this important element of the foundation. Most of the programs have served Native American communities in Alaska, Wyoming, Nebraska, and the American Southwest (Fig. 1). There was even an Outreach in Chicago!

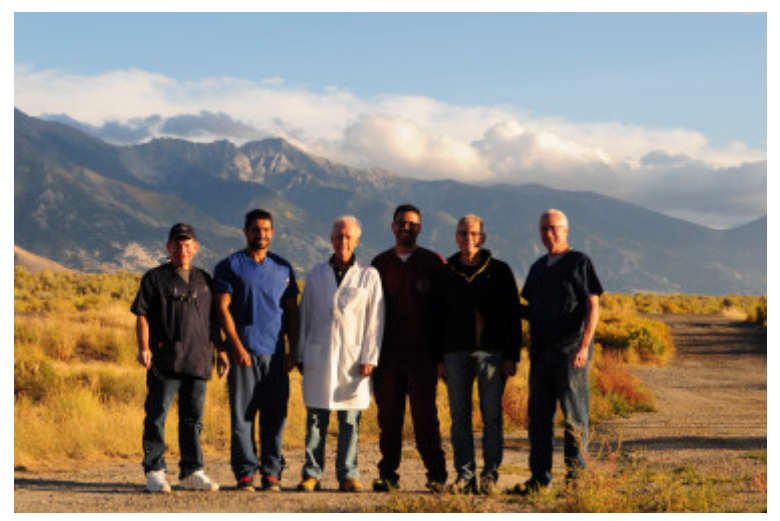

Figure 1. (Left-to-right) Drs Geoffrey Thompson, Ali Ramadhan, Edward Plekavich, Tony Sierra, Ken Sobczak, Stephen Wagner (Confederated Tribes of the Goshute Reservation, Nev.).

More recently, the academy formed an International Outreach Program, with teams travelling to Africa and Mexico. Academy fellows, Drs Izchak Barzilay and David Chvartszaid, as well as, Academy Aspirant Dr Effrat Habsha visited rural Uganda. In 2016, Dr Barzilay initiated an innovative program which focused on tooth replacement with same day prostheses. This extraordinarily rare treatment to the Ugandan villagers quickly gained popularity. In 2017, the team expanded, and the number of patients seen and prostheses fabricated increased. Over the course of the 8-day mission, a new clinic was established in a new community each day. Using generators in make-shift dental operatories, the prosthodontic team completed up to 16 prostheses per village per day. 
Some of the original members of the outreach recall stories of sleeping on floors or in drafty trailers (Figs. 2, 3), making-do with the available resources at the outreach sites in MacGyver fashion, and allday drives to fetch and return a pizza in time for dinner. Academy fellows Eric Rasmussen, Ed Plekavich, Tom Taylor, Sree Koka, Steve Sadowsky, Ken May, Jim DeBoer, John Agar, Paul Martinez, Jeff Rubenstein, and Tom Salinas have been doing this for a long time (Fig. 4). Today, groups often work in a modern dental clinic with water, power, and lighting (Fig. 5); however, it is still not uncommon to seat the patient in a folding chair, work out of a tent, or use a rasp meant for shaping a horse's hoof as a cast trimmer (Figs. 6, 7). Several of the groups take dental students and prosthodontic residents (Fig. 8), which instills the belief that giving back is an important principle. The work is significant and has been recognized by the President of the United States in a commendation letter to the Outreach Program and by the American Dental Association, who helped the Outreach Program celebrate its first 25 years by running a front-page story in the ADA News.

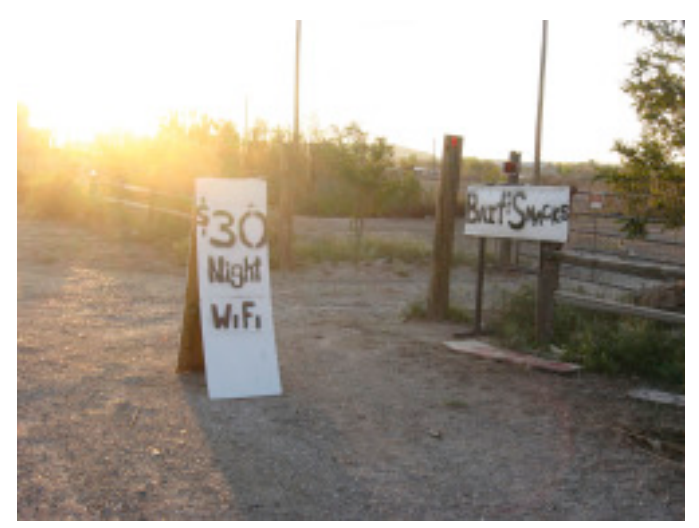

Figure 2. Sign in front of typical lodging (Montezuma Creek, Utah).

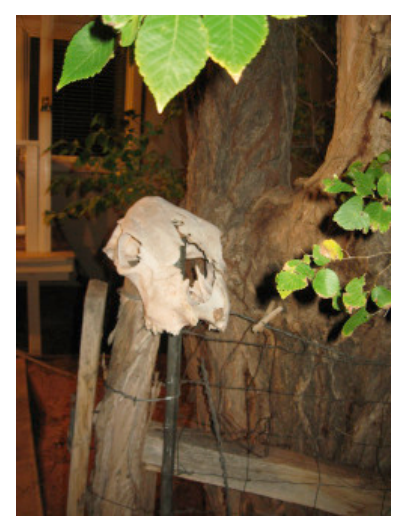

Figure 3. Signpost in front of lodging (Mexican Hat, Utah). 


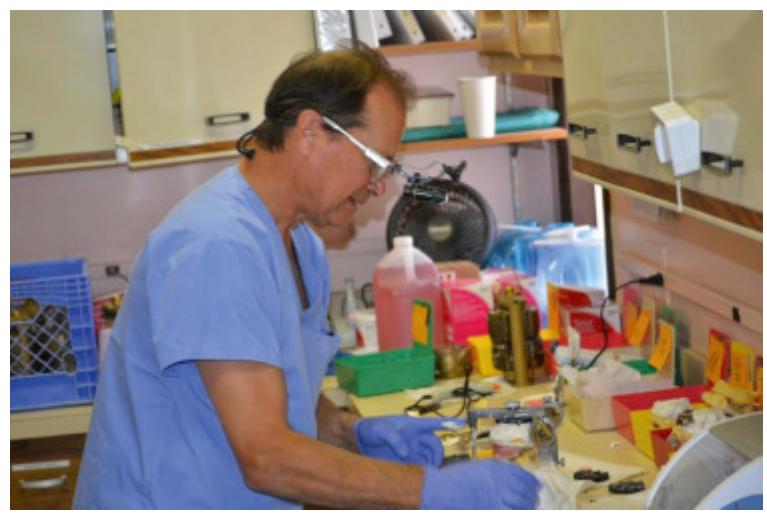

Figure 4. Dr Eric Rasmussen in the dental laboratory (Montezuma Creek, Utah).

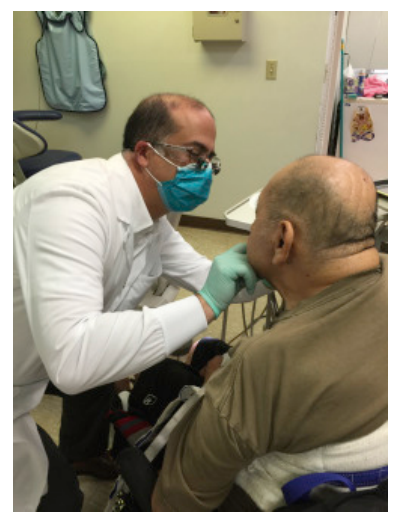

Figure 5. Dr Thomas Salinas evaluates dentures.

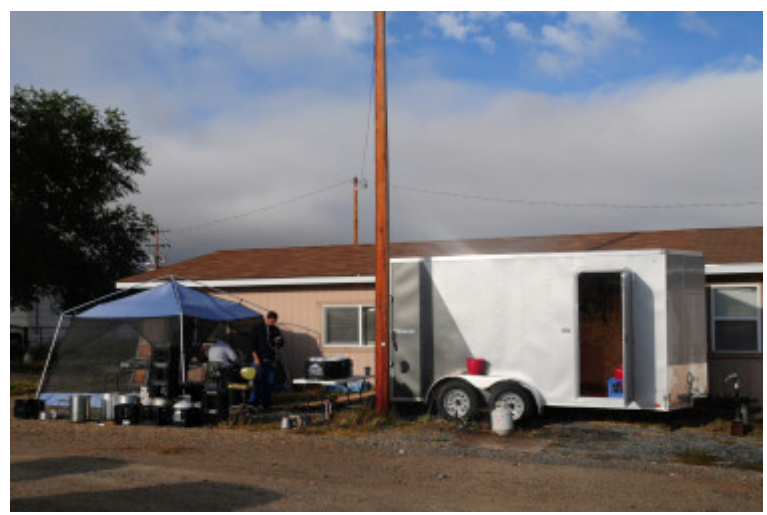

Figure 6. Trailer and tent used for making dentures on site (Confederated Tribes of the Goshute Reservation, Nev.). 


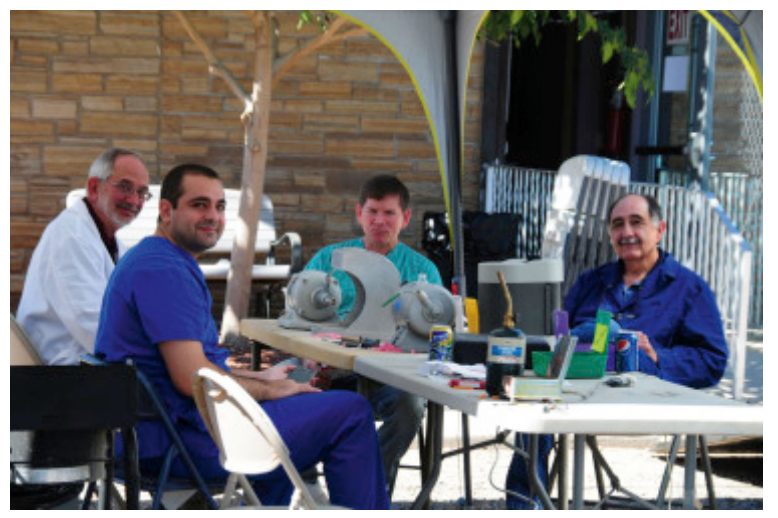

Figure 7. (Left-to-right) Drs James Deboer, Renos Argyrou, Geoffrey Thompson and Mr. Ted Medina, laboratory technician (Montezuma Creek, Utah).

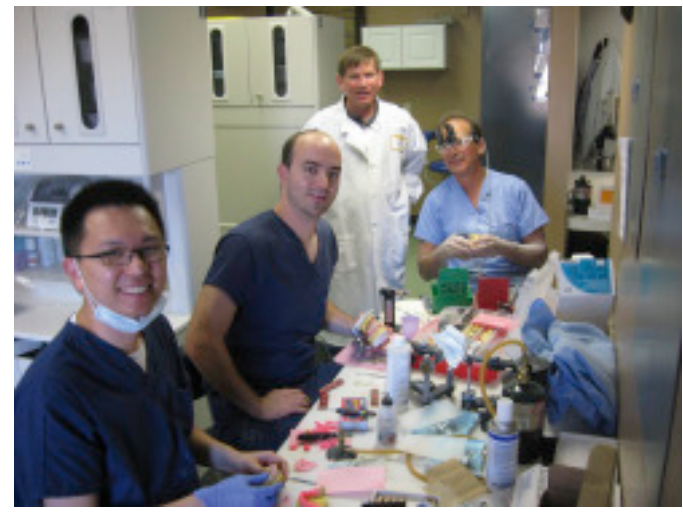

Figure 8. Prosthodontic residents John Chou, Steve Koutnik, Program Director Geoffrey Thompson (center), Eric Rasmussen (right) (Montezuma Creek, Utah).

Member, Dr Ed Plekavich sums up the experience of the outreach groups very well with this quotation, "I'm convinced the giver gets more out of it than the recipient." It has been our honor and a privilege to serve and to meet all the fine people who have supported our operation. We look forward to the next 25 years of service. 